\title{
Security Methods in the Art and Science using Spectroscopy in the Visual and Near Infrared Range
}

\author{
Vilko Žiljak, Lidija Tepeš Golubić, Jana Žiljak Gršić, Denis Jurečić
}

\begin{abstract}
Near infrared $Z$ values are determined with spectroscopy of colorants, which are used in security charts, printing of documents and banknotes. A new application of security methods in informatics is being observed in this article. The processes of dyeing of fabrics are being controlled by programming twin dyes. Two different mixtures of dyes have been created for the same color. They differ in light absorption only in NIR area. The given, desired difference in their values of light absorption and NIR spectrum has been achieved. Conversely, those are two dyes of different mixture but with the same color parameters in the visual spectrum. The dyes have identical spectra graphs of light absorption in the visual area. The experimental result has been shown in the gallery with infrared pictures and through the design of textile clothes that carries the hidden information. The design with text "IJNTR VZ security" has been analyzed by forensic light blockages from 400 up to $1000 \mathrm{~nm}$.
\end{abstract}

Index terms - Twin colors and dyes, invisible information, NIR spectrum, security graphics, INFRAREDESIGN.

\section{INFORMATION IN VIS AND NIR SPECTRUM}

The information system on documents contains dual states. In this paper, the design, visual art in general, is being spread to the Near Infrared area. Around us there are NIR security cameras with different performances. In practice, the term "video surveillance" is used. Clothes with a design for selective observation with NIR registration are being presented (Fig. 1).

Documents for public (state) application and for personal notation of print on a printer are being developed in FotoSoft laboratory [1]. The originals of our KUNA banknotes [2] have a series of graphic technologies with protective line graphics that have been developed as computer graphics [3]. The development of computer graphics started in Zagreb in 1970 at the time of "New tendencies".

The INFRAREDESIGN processes have been applied to postage stamps with the programming of VZ security printing process [4]. Those graphics are small in format so additionally, through IRD technology, expansion of information in the invisible near infrared spectrum has become available.

Vilko Žiljak, University of Zagreb, Faculty of Graphic Arts, Zagreb, Croatia

Lidija Tepeš Golubić, Zagreb University of Applied Sciences, Zagreb, Croatia

Jana Žiljak Gršić, Zagreb University of Applied Sciences, Zagreb, Croatia

Denis Jurečić, University of Zagreb, Faculty of Graphic Arts, Zagreb, Croatia
A permanent exhibition of dual images that are being observed with dual cameras with which both the artwork and the exhibition visitors are simultaneously being observed has been set in a gallery named "Z" ( $\mathrm{Z}$ for Zelina, a town in Croatia). [5] The digital record is continuous and selective; in the visual (V) and near infrared spectrum.

Video surveillance that is discreet, non-intrusive: on the streets, in galleries. The idea in this paper is to create an information system that gives a new approach to the planning of clothes dyeing and intervention marking of security graphics in the urban environment. Information system for NIR spectrum is being developed by studying the expanded features of dyes for different application. The term " $\mathrm{Z}$ " is being separated from the broad NIR spectrum; in the $1000 \mathrm{~nm}$ [6]. A numerical value $\mathrm{Z}$ is being joined to each dye, substance from the area of flora, fauna and minerals. This is a reference point for a broader description of the substance, that is, a value of light absorption at $1000 \mathrm{~nm}$. This is information for designers, artists on their path of a successful orientation for the planning of an invisible dual image. In this paper an acronym "VZ" is being used when describing dye separation, dual digital record, graphic design, VZ animation, art painting and security graphics.

The expanding of the VZ ideas is being accepted by visual artists in order to express intimate, unique contents through a multi-tone monochrome $\mathrm{Z}$ graphics that is invisible to the naked eye. The paintings in the galleries are not being studied only as a passive security recordation in NIR spectrum. The double VZ world has initiated the idea of the creation with a VZ mark.

The duality of a new technology of mixing Acrylic dyes is being based on spectroscopic dye values in VIS and NIR areas. A video that shows pictures in continuous observance with light blockages from the visual state to the near infrared isolation of a hidden image has been performed for art paintings [5]. The hidden text (picture 1) on the dress is: „TECHNOLOGY, AND RESEARCH INFRARED IMAGING, IJNTR - VZ security, CROATIA ART, NEAR INFRARED, HIDDEN IMAGES“. Fashion design is being freely spread to the sphere of intimate uniqueness, it shows the power of digital print with VZ programming technology. Dual solutions have been developed for different types of uniforms with a goal of hiding and detection of the desired information [7]. The unique solutions are a mix of two pieces of information: visual and the one hidden from the naked eye [8]. Textile print has been performed with a DURST printer plotter of high speed and dye properties resistant to washing [9]. 


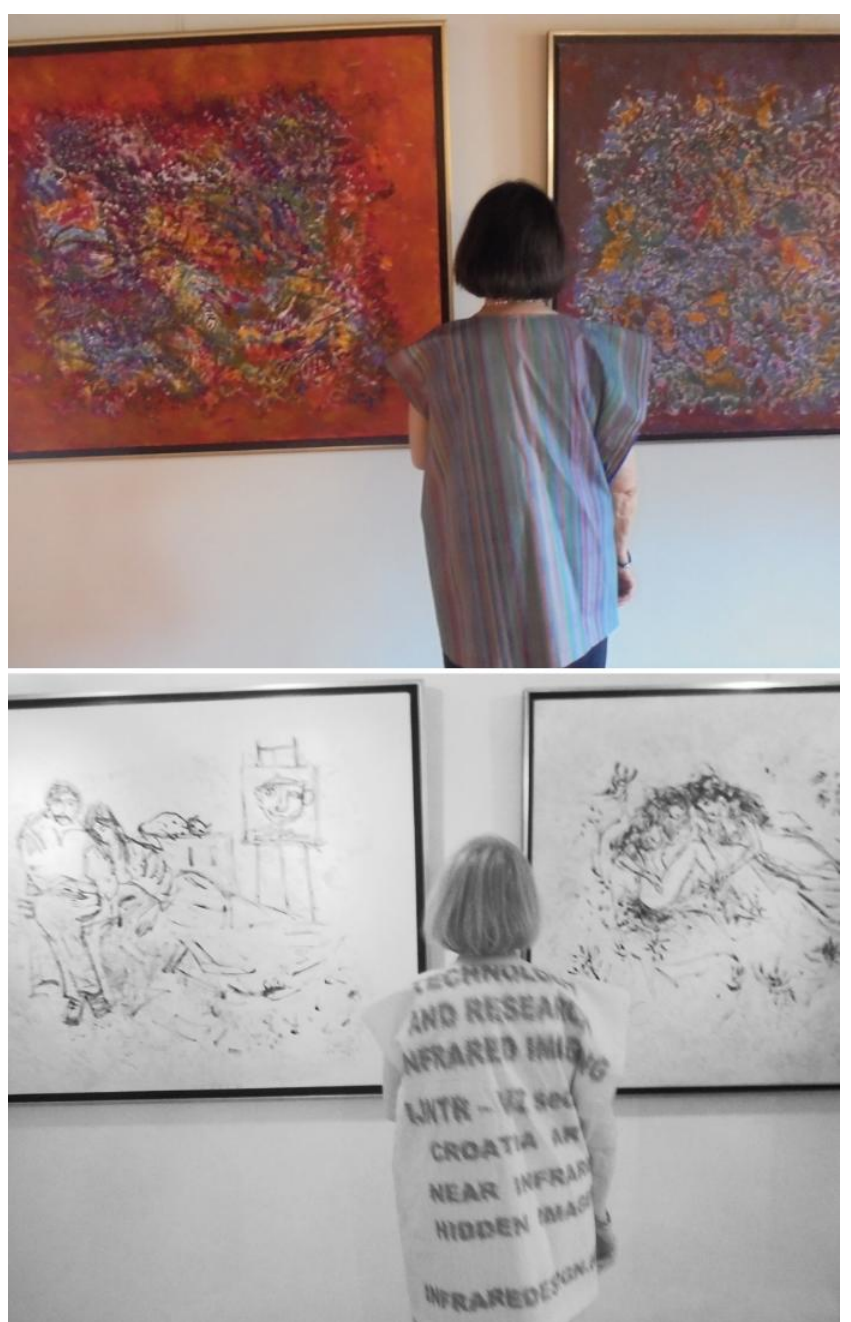

Fig. 1. Zelina, http://www.gallery-hr.com/InfraredArt/ index.htm\#engleski

Animation: /n115.mp4 and /n106.mp4 [5]

The experimental work on determining dye twins has been developed at institutions of higher education in order to determine "VZ Color Setting" [10]. The base of new duo groups of dyes is the basis for printing technology with a process set of dyes [11].

\section{SPECTROSCOPY OF PROCESS TWIN DYES AND SPOT DYES}

The area of process dyes for printing reproduction (Fig. 1) has been included into the research. The collection of CMYK dyes enables simulation of a colored substance in two spectra. The need for studying dyes through a graphic demonstration of their spectrum of light absorption in the visual and near infrared area is being demonstrated in this paper. The clothes are produced on digital machines that are ideal for performance of individual information that is managing a VZ color separation. VZ preparation for dye mixing is being managed by VZ program solutions that are adapted to the material and print technology. The same thinking has been used for the protection of securities and graphics that disable scanning and conventional CMYK reproduction. The newer solutions are focused on the expanding of the software on the relation computer / printer which is named "printer driver". The software solution for security graphics, as for example a vignette (Fig. 4), is being built into the printer driver program in order for the print on the printer to contain a security mark
(Tab. 1). Their spectroscopic information on the radiation absorption in VIS and NIR area is shown on the spectrograms of Fig. 2 and 3.

Table 1. Solution of twins and dyes for security graphics (Figure 4.)

\begin{tabular}{|l|l|l|}
\hline color & RGB & CMYK \\
\hline 1 violet $\mathrm{V}$ twin & $119,52,104$ & $62,81,36,0$ \\
\hline 2 violet $\mathrm{Z}$ twin & $119,52,100$ & $30,68,0,40$ \\
\hline 3 green deep $\mathrm{V}$ & $125,183,46$ & $70,0,100,0$ \\
\hline 4 green light $\mathrm{V}$ & $0,177,20$ & $50,10,90,0$ \\
\hline 5 blue $\mathrm{V}$ & $38,83,164$ & $90,60,0,0$ \\
\hline 6 deep blue $\mathrm{Z}$ & $52,0,90$ & $80,90,0,30$ \\
\hline 7 red $\mathrm{Z}$ & $149,0,0$ & $0,90,70,40$ \\
\hline
\end{tabular}

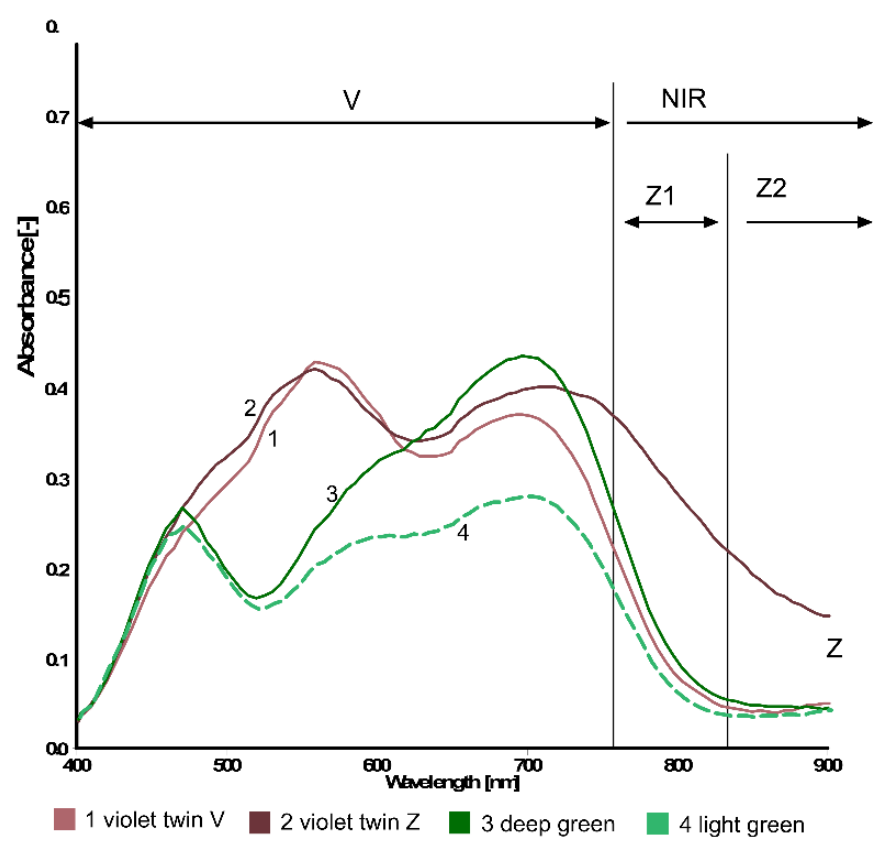

Fig. 2. Spectra for violet twin and green colors

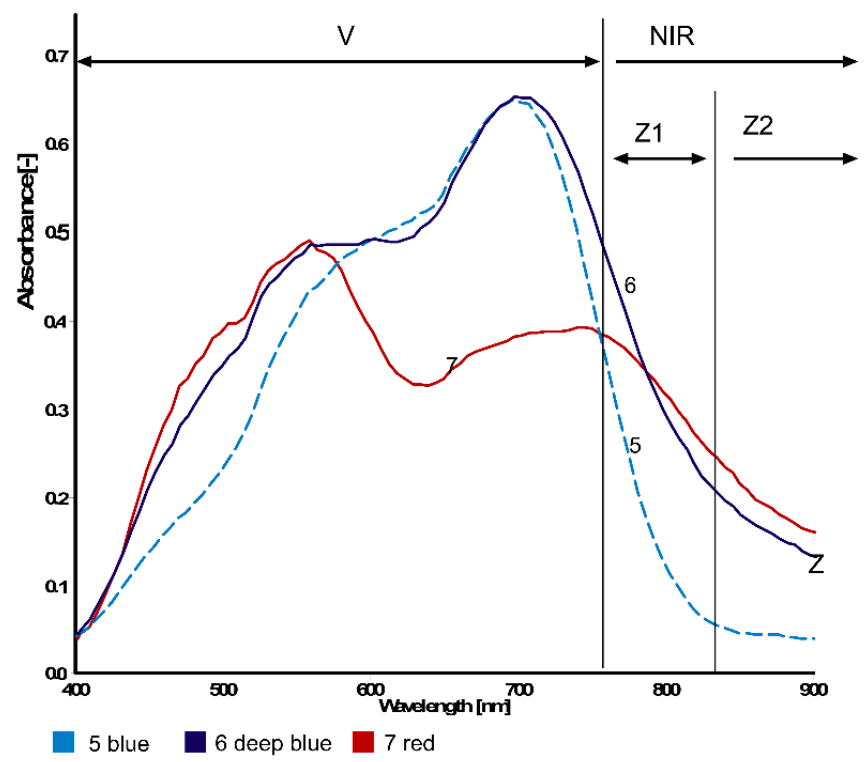

Fig. 3. Light absorption for line graphics 
Colors and dyes are shown through a spectrogram. Violet twin dyes (1 and 2) are different in NIR area. Their radiation absorption values at 900 nanometers are manifested as those dyes that hide the information (Fig. 2) in the visual spectrum. Their graphs are very similar in that spectrum. The separation begins after 700nm. Two different green dyes (used in a security vignette, Fig. 4) cannot be seen with a $\mathrm{Z}$ camera because their NIR radiation absorption properties are minimal and identical after $850 \mathrm{~nm}$. The two green colors have the same properties in the area from 400 to $550 \mathrm{~nm}$ where the absorption is dominant due to a high coverage with a yellow component [12].

The transition from the visual to the infrared spectrum has been recognized as the area of mixing information. Recordings made with a forensic camera and filters at 715 , $735,780,830,850$ and 1000 nanometers are registered in NIR spectrum [13]. The recordings in VIS spectrum provide excellent information about establishing the authenticity of the artwork because the mutual quantity of blue components in dyes can be recognized. Many dyes for art painting have their characteristic manifestation exactly in that field of light. For example, there are two peaks for the green color, that is, two maximums if that color has been derived from the mix of the yellow and the blue color. For every new mixture of the green color, this graph is also characteristic due to its own information about the position of the first peak. Similar reflections can also be found in the application of printing technology. The green color is exclusively a result of mixing the cyan and the yellow color.

In $\mathrm{Z} 1$ area there is a significant reduction of the absorbance value (after $750 \mathrm{~nm}$ ) for all the dyes of fine arts and process printing dyes [12]. The reason for separated measurements of absorption of spectrum Z2 (after $850 \mathrm{~nm}$ ) has been the equalization of absorption values for dyes that are being discussed in this paper.

Spectra graphs indicate the direction of the correction of dye composition during the determination of twin dyes. The previous analysis [12] of process dyes for printing help in the iterative procedure that includes: measuring the color equality (delta E), in reprint, and in spectrography. It is additionally remarked that each new paper/toner set has a slightly different solution for every color tone. Mass application of security printing is being performed in offset technique with spot dyes that are being mixed before printing. The formula of the composition of dyes for making securities is a secret of the printing house [2]. Spectroscopy methods give information for every $5 \mathrm{~nm}$ and that is information that even the most complicated dye recipes can be entered if the components of the final solution are process dyes.

The forensic camera with 24 selective filters in UV, VIS and NIR area [13] has been the base for the calibration of our filters in laboratory procedures of processing new photo cameras, and that have been performed with only one filter [14]. A value $Z$ at $1000 \mathrm{~nm}$ has been chosen as a reference wave length with application on modifying video and photo cameras. The database about the property of absorption of NIR wave lengths for different materials with the identical, standardized, digital recording is being expanded [15]. Dyes for application of individualized hidden information are being categorized according to the $\mathrm{Z}$ values.

\section{SECURITY GRAPHICS}

The demonstration of light absorption in two spectral areas is being presented with a realization of a security vignette. This graphics (Fig. 3) has been realized with the dyes from Table 1.
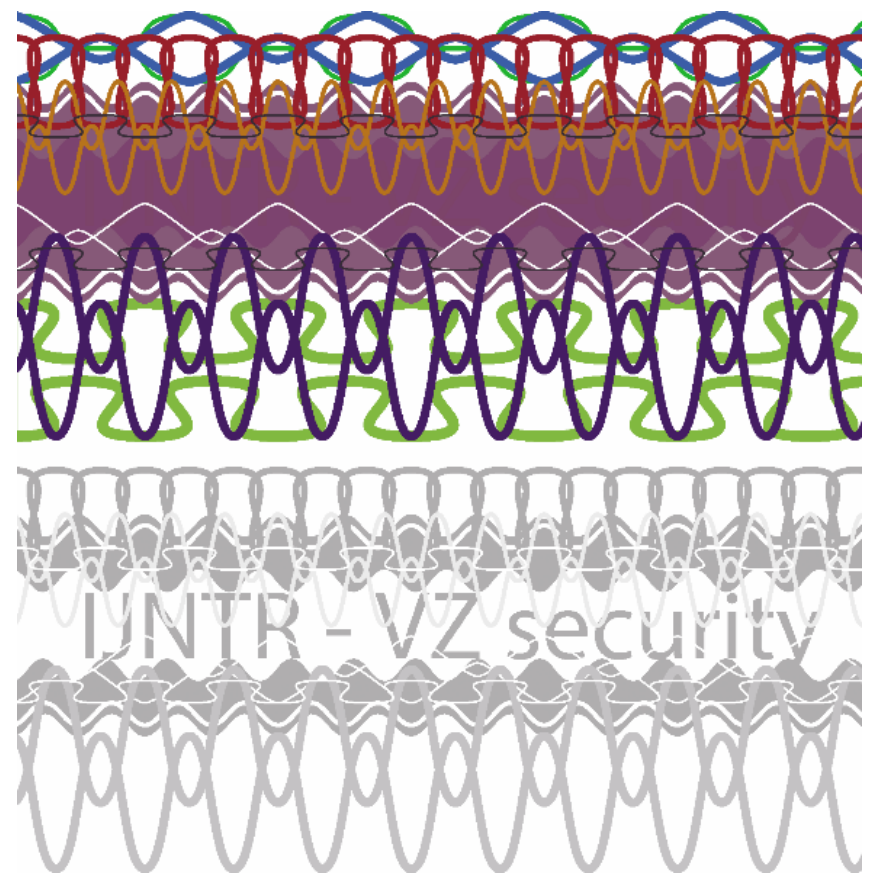

Fig. 4. IJNTR document seen by the naked eye VIS and adjoined hidden $\mathrm{Z}$ design

Security graphics with hidden letters "IJNTR - VZ security" has been designed with lines that have been planned especially for the visual and NIR area. Middle part is covered in color (color 1 and 2) that shall be read by the scanner as RGB with values: $119,52,104$ or L*a*b: $33,35,-17$. The dye is being performed with $\mathrm{V}$ and $\mathrm{Z}$ twins whose parameters in the process proportion of the dye are: CMYK: 30, 62, 0, 40 percent or $\mathrm{L}^{*} \mathrm{a} * \mathrm{~b} 32,25,-15$ for the hidden text. The text environment, which cannot be seen by NIR camera, has the following CMYK parameters: 2, 81, 36, 0 percent of coverage. The small difference between the colors (1 and 2) still does not allow our eyes to recognize the text. This hidden text is not recognized even with conventional scanners.

Two green colors and blue color (3, 4 and 5) have been used for the lines on the upper and lower part of the vignette. They cannot be recognized with a NIR camera. Line graphics with a deep blue (6, down) and red color (7, on top) respond to the NIR camera.

The text is being recognized by a NIR camera. The record of this security graphics has been examined with a forensic camera Projektine [13]. Three records at 570, 695 and $830 \mathrm{~nm}$ have been chosen in the article (Fig 5). At the blockage of 570 $\mathrm{nm}$ there is no more yellow component [11], the recording at $695 \mathrm{~nm}$ does not have information about magenta. Hidden text $\mathrm{Z}$ appears at these blockages because there is a lack of one (Y) that is, two dyes (Y, M) in its environment. Information about the absorption of cyan dye stayed at 695 $\mathrm{nm}$. In the beginning of $\mathrm{Z} 2$ area at $830 \mathrm{~nm}$, the graphics is 
clearly visible, cleaned from colorful dyes C, M, Y. NIR light absorption property for carbon black dye $\mathrm{K}$ is the base of the idea about designing a hidden graphics for printing industry, protected printing, technology of hiding information on documents and securities.
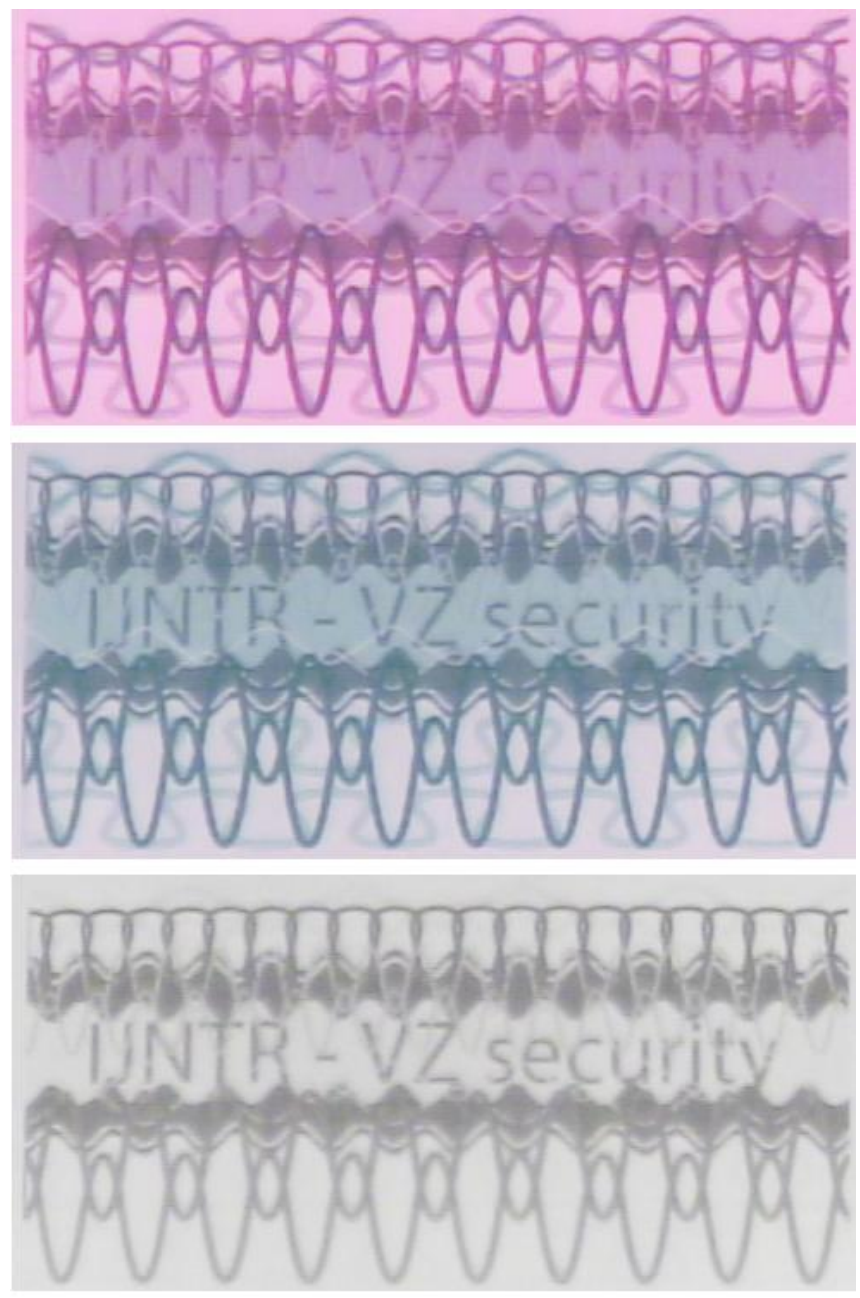

Fig. 5. Forensic record in VIS and NIR spectrum

Security graphics has been recorded in around twenty light blockages in the range from 400 to 1000 nanometers [13]. These data are information for video presentation of transformation the VZ graphic in VIS and NIR spectrum.

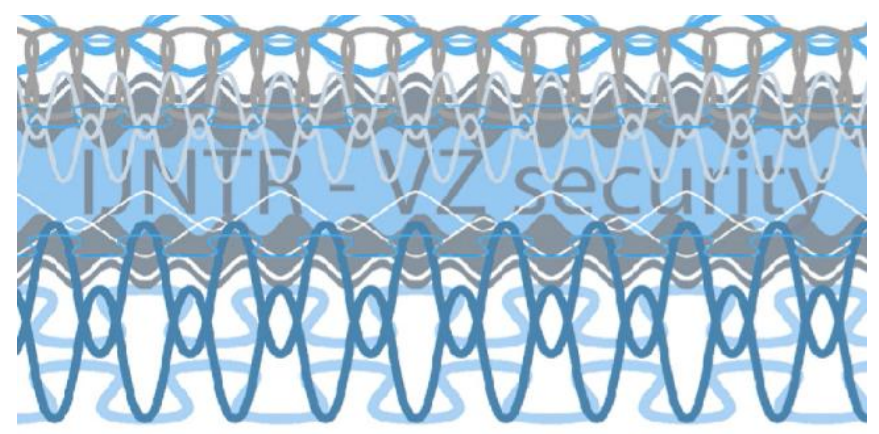

400 700 1000

Fig. 6. Animation as the basis of NIR experiments: http://jana.ziljak.hr/IJRj01.mp4

\section{CONCLUSION}

The application of recognizing properties of absorption light from colorants up to $1000 \mathrm{~nm}$ with a print in Ink-jet technology is being expanded. Since we can already see people and nature with different response in NIR spectrum, the idea is to create a new fashion clothing, and document design with the intention of "VZ informing". A dual picture is being developed, that is, dual painting where two images are being selectively observed with VZ cameras. With the development of the group of twin dyes, and for each printing technology separately, application of VZ technology in the protection of documents on personal level is being opened. Unique, protected VZ design shall be applied in the IT industry at numerous levels of application.

\section{REFERENCES}

[1] J. Z. Vujic, S. Crnjac, O. Mitrovic, Development of the new protection processes and services for secure printing, 14th International design conference - DESIGN 2016; Cavtat, Dubrovnik - Croatia, May 16 - 19, 2016. ed: D. Marjanoviæ, Faculty of Mechanical Engineering and Naval Architecture, Zagreb, Proceedings 429, pp:2197 - 2204; ISSN 1847-9162, ISBN 9771847916007

[2] https://www.hnb.hr/novac/novcanice National Bank of Croatia, Vilko Žiljak

[3] http://www.gallery-hr.com/Vilko/ http://www.msu.hr/\#/hr/tag/vilko-ziljak/ Museum of Contemporary Art, Vilko Žiljak

[4] M. Rudolf, N. Stanic Loknar, I. Z. Stanimirovic, Infrared steganography with individual screening shapes applied to postage stamps with security features ; Technical Gazette, 08/2015; 22(4):939-945.

[5] Gallery of Zelina, animation VIS/NIR: www.nada.ziljak.hr/n106.mp4

[6] V. Žiljak, K. Pap, I. Z Stanimirovic, J. Vujic, Managing dual color properties with the Z-parameter in the visual and NIR spectrum. Infrared physics \& technology 55 / 4, pp. 326-336 ;2012 Elsevier B.V ; DOI: 10.1016/j.infrared.2012.02.009

[7] V. Ziljak, D. Agic, Rajendrakumar Anayath; Broadening INFRARED technology on cotton fabric coloration with double information ability in visual and infrared spectra; TTEM, 11/ 1, 2016, ISSN 1840-1503, e-ISSN 1986-809X p3-10, http://www.ttem.ba

[8] K. Pap, I. Ziljak; J. Vujic, Image Reproduction for Near Infrared Spectrum and the Infraredesign Theory, Journal of Imaging Science and Technology, 54/1, pp. 10502-1-10502-9(9) 2010

[9] A. Bernasek Petrinec, J. Grsic, S.Stanacev Bajzek, Infrared painting in fine art of Nada Ziljak, 5th International Multidisciplinary scientific conference on social science \& arts, SGEM 2018, Conference proceedings pp:391-396, Vol.5, Science and art, Issue 6.1/ Contemporary arts, ISBN 978-619-7408-34-8 ISSN 2367-5659 DOI: $10.5593 /$ sgemsocial2018H/61

[10] I. Pogarcic, A.Agic, M. Matas, Evaluation of the colorant twins for the neutral grey spectra in infrared graphic procedure; Technical Gazette 23, 6(2016), p:1659-1664; ISSN 1330-3651, ISSN 1848-6339; DOI: 10.17559/TV-20150303132036 ; Hrcak ID: 169526

[11] J. Ziljak, D. Jurecic, V. Ziljak, Packaging Design with Hidden Near Infrared Colour Separation, Technical Gazette, 25/3 pp: 211-215, 2018. ISSN 1330-3651 (Print), ISSN 1848-6339 (Online) https://doi.org/10.17559/TV-20170705114921

[12] J. Z. Grsic; Near infrared spektroskopy in print tehnology, Polytechnic \& design 5/1, 2017. pp:32-36; DOI: 10.19279/TVZ.PD.2017-5-1-05

[13] Projectina Docucenter 4500, \& PAG B50, http://forensictechnology.com/projectina/ Switzerland

[14] I. Rajkovic, V. Ziljak, Usage of ZRGB video camera as a detection and protection systemand development of invisible infrared design; Polytechnic \& Design,. 4/1, 2016. pp: 54 - 59; ISSN 2459-6302; ISSN ;1849-1995 ; DOI: 10.19279/TVZ.PD.2016-4-1-07

[15] V. Ziljak, K. Pap, I. Ziljak, CMYKIR security graphics separation in the infrared area, Infrared Physics and Technology 52/2-3, ISSN 1350-4495, Elsevier B.V. DOI:10.1016/j.infrared.2009.01.001, p: 62-69, (2009) http://linkinghub.elsevier.com/retrieve/pii/S1350449509000103 


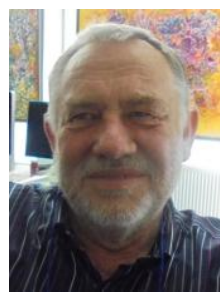

Professor Emeritus, Vilko Žiljak, Ph.D. (1946), University in Zagreb. He graduated from the mathematical and natural science faculty in Zagreb, with a major in Physics. He obtained his doctorate in 1981 at the Faculty of Electrical Engineering and Computing. His domain: modeling and simulation, graphic technology, computer science, computer graphics. He has published 10 books and 505 papers. He has won 105 awards for inovation. Specialization: document protection technology. He is the author of Croatian kuna banknotes. e-mail: vilko@ziljak.hr

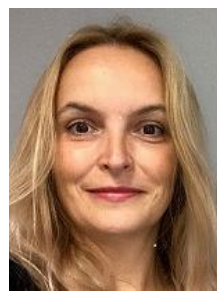

Lidija Tepeš Golubić, Ph.D. (1975), is a senior lecturer at Zagreb University of Applied Sciences. She has graduated from the Faculty of Humanities and Social Sciences, University of Zagreb, where she also received her $\mathrm{PhD}$ at the Department of information and communication sciences. The field of interest is computer assisted linguistic analysis of German loanwords and linguistic borrowing generally, computer assisted text analysis of contemporary web texts. She is at the same time coauthor of the several paper dealing with the InfraRed design and messages hidden in painted canvas and other materials. e-mail: lidija75@yahoo.com

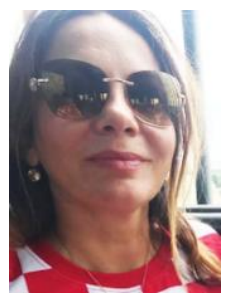

Associate profesor, Jana Žiljak Gršić, Ph.D. (1972). Professor at Zagreb University of Applied Science., University North and Faculty of Graphic Arts. She obtained her doctorate in 2006 at the University of Zagreb. She has published a book "Security graphics of documents and securities" and 80 scientific and professional papers. Her domain are information science, graphic technology, graphic design.e-mail: jana@ziljak.hr

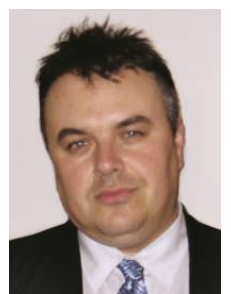

Denis Jurečić, Ph.D. (1966), University of Zagreb, Faculty of Graphic Arts. He obtained his doctorate in the area of graphic technology, in 2015. He teaches in the field of designing graphic products, specialization: packaging, security printing. He has published 60 scientific papers. e-mail: denis.jurecic @ grf.hr 